\title{
UMA PERSPECTIVA COLABORATIVA DA CADEIA DE SUPRIMENTOS PARA APOIAR A INDÚSTRIA 4.0
}

\section{A SUPPLY CHAIN COLLABORATIVE PERSPECTIVE TO SUPPORT INDUSTRY 4.0}

\author{
Henrique Lima Santana*E-mail: hlsantana@unimep.br \\ Maria Rita Pontes Assumpção* E-mail: maria.assumpcao@unimep.br \\ Maria Célia de Oliveira* E-mail: maria.oliveira32@unimep.br \\ *Universidade Metodista de Piracicaba (UNIMEP), Santa Barbara do Oeste, SP
}

Resumo: A necessidade de fornecimento de insumos para a Indústria 4.0, que está permeada pelo avanço tecnológico dos dispositivos sensoriais, virtualização de ativos, loT, Big Data Analytics, CPS, Data Mining, RFID, loS e computação em nuvem, requisita avaliação das iniciativas da cadeia de suprimentos que podem ser colaborativas para atender as demandas dos recursos. $\mathrm{O}$ artigo apresenta revisão da literatura sobre a Indústria 4.0 e a cadeia de suprimentos, e ainda uma análise bibliométrica para responder a seguinte questão: como a cadeia de suprimentos poder colaborar com a Indústria 4.0? Um questionário autoaplicável envolvendo liderança especializada em suas áreas é desenvolvido para obter informações sobre critérios estratégicos, organizacionais, tecnológicos e de segurança da informação, que posteriormente, é utilizado no método AHP para priorização das alternativas colaborativas. Os resultados demonstram que a falta de conhecimento tecnológico, segurança da informação e problemas de transparência na comunicação estão entre as ações prioritárias da cadeia de suprimentos para antever soluções colaborativas que possam reduzir ameaças futuras e acompanhar os avanços tecnológicos da quarta revolução industrial.

Palavras-chave: Indústria 4.0. Cadeia de Suprimentos. Medidas Colaborativas. Tecnologia industrial. Tomada de Decisão Multicritério.

Abstract: The need to provide inputs for Industry 4.0, which is run through by the technological advancement of sensory devices, virtualization or digital twins, IoT, Big Data Analytics, CPS, Data Mining, RFID, loS and cloud computing, requires evaluation of the supply chain's initiatives that can be collaborative to meet the resources demands. The article presents a literature review on Industry 4.0 and the supply chain, as well as a bibliometric analysis to answer the following question: how can the supply chain collaborate with Industry 4.0? A self-administered quiz involving specialized leadership in its areas is developed to get information on strategic, organizational, technological and information security criteria, which is then used in the AHP method to prioritize collaborative alternatives. The outcomes demonstrate that the lack of technological knowledge, information security and communication transparency issues are among the priority actions of the supply chain to foresee collaborative solutions that can reduce future threats and keep up with the technological advances of the fourth industrial revolution.

Keywords: Industry 4.0. Supply chain. Collaborative measures. Industrial technology. Multi-criteria Decision Making (MCDM).

\section{INTRODUÇÃO}

Com a modificação das características de consumo, questões como mercado- 
ria com flutuação da demanda e alto nível de customização, impactaram nos sistemas regulares de produção. Os processos produtivos devem estar conectados por meio de informações integradas para auxiliar à decisão de ressuprimento dos recursos (BAUER, SCHOONMANN e REINHART, 2017).

O termo Indústria 4.0 é um conceito que abrange a cadeia de valor de uma organização, permeando tecnologias, sistemas e processos que permitirão atender a customização em massa por intermédio da flexibilidade em seus projetos, sem sofrer impactos estruturais (WANG, et al., 2017).

Afastando-se dos sistemas mecânicos tradicionalmente adotados, os processos produtivos da Indústria 4.0 utilizam novas tecnologias no setor de manufatura, direcionando as linhas de montagem para conceitos sofisticados e automatizados para atender a dinâmica das exigências dos clientes (SACHDEVA, et al., 2018).

Contudo, as iniciativas da Indústria 4.0 podem influenciar todo o sistema de negócios, transformando os meios pelos quais os produtos são projetados, produzidos e entregues (LUTHRA e MANGLA, 2018).

Para isso, a indústria 4.0 requer sistemas de informações integrados que interajam com as organizações, dispositivos e os operadores (CAMARINHA-MATOS e AFSARMANESH, 2014). Por ser orientada mediante dados em tempo real e composta por sistemas ciber-físicos inteligentes, requer também que os equipamentos, processos e disponibilidade de recursos estejam fortemente conectados (O'DONOVAN, et al., 2018).

Desta forma, um dos desafios da Indústria 4.0 é o desenvolvimento colaborativo com a cadeia de suprimentos, pois necessita que o fornecimento dos recursos seja suficientemente flexível, e assim colabore com os requisitos desta revolução industrial - controle descentralizado em larga escala e tomada de decisão autônoma (WANG, et al., 2016).

Além disso, os processos logísticos devem atuar de forma integrada para 0 fornecimento no momento e na quantidade requisitados, e ainda fornecer os recursos na sequência de produção determinada (JUHÁSZ e BÁNYAI, 2018).

Na Indústria 4.0 é crucial analisar os impactos da cadeia de suprimentos desde o pedido até a entrega do recurso (TJAHJONO, et al., 2017). 
Para suportar estas necessidades, a cadeia de suprimentos precisa tomar medidas para compreender as tecnologias envolvidas na indústria 4.0, e assim, analisar o custo/benefício sobre os investimentos requisitados para acompanhar a revolução tecnológica (LUTHRA e MANGLA, 2018). Dado que, estas tecnológicas estão modificando os paradigmas tradicionais de produção e disponibilizando à cadeia de suprimentos uma visão global sobre o processo produtivo (BONAVOLONTA, et al., 2017).

Bem como, em razão do aumento do fluxo de dados gerado pela Indústria 4.0, a cadeia de suprimentos precisa adotar medidas não apenas pela própria segurança de dados, mas também para preservar a relação com seus parceiros e clientes (MÜLLER, BULIGA e VOIGT, 2018).

Neste modelo, é necessário também que a cadeia de suprimentos assuma medidas que promovam um alto nível de visibilidade das informações, e que desta maneira extrapole os limites internos da empresa visando prover transparência operacional que resulte na confiabilidade de fornecimento para a Indústria 4.0 (SCHUH, et al., 2017).

Estas ações colaborativas são necessárias, pois a cadeia de suprimentos apresenta melhores resultados quando seus membros cooperam entre si (SIMATUPANG e SRIDHARAN, 2018).

Para avaliar estas medidas colaborativas, o artigo apresenta uma revisão da literatura sobre as tecnologias envoltas na Indústria 4.0 e os desafios da cadeia de suprimentos para contribuir com a quarta revolução industrial. Posteriormente, é realizada uma análise bibliométrica para encontrar artigos que forneçam exemplos de quais medidas colaborativas da cadeia de suprimentos possam ser úteis para a Indústria 4.0, e em seguida, é desenvolvido um questionário autoaplicável (visão de especialistas) em conjunto com o método AHP (Analytic Hierarchy Process) para priorizar tais iniciativas. Tudo isso visando responde a seguinte questão: como a cadeia de suprimentos poder colaborar com a Indústria 4.0? Por fim, são apresentados os resultados e a conclusão do artigo.

\section{REVISÃO DA LITERATURA}

A fundamentação teórica do trabalho está dividida em duas seções. A primeira 
trata da Indústria 4.0 no tocante as tecnologias envolvidas e os requisitos para atingir os estágios de maturidade desta revolução industrial. A segunda trata da cadeia de suprimentos da Indústria 4.0 no tocante a necessidade de integração para compor medidas colaborativas, desafios na implementação de uma cadeia de suprimentos colaborativa (segurança de dados, transparência da informação e conhecimento das tecnologias) e aplicações práticas de medidas colaborativas da cadeia de suprimentos utilizando tecnologia semelhante à Indústria 4.0.

\subsection{Indústria 4.0}

Em razão da forte demanda por customização dos produtos e da necessidade de flexibilização das condições produtivas, o termo "Indústria 4.0" surge no projeto do governo alemão para promover a informatização da manufatura. Posteriormente, a Acatech (German Academy of Science and Engineering) apresenta agenda de pesquisa e recomendações visando desenvolver processos de monitoramento e tomada de decisão inteligente (BMBF, 2018).

Desde a sua cunhagem na feira comercial de Hannover em 2011, a Indústria 4.0 tem inspirado pesquisa sobre o futuro da manufatura e modificado o plano de investimento em diversos países. Ainda em sua primeira publicação sobre a Indústria 4.0, a Acatech descreve o tema como uma nova visão que, embora impulsionada pela disponibilidade tecnológica e capaz de resolver problemas considerados insolúveis, necessita ser modelada para as diversas realidades locais e culturais (PFEIFFER, 2017).

Decorrente dos efeitos da Indústria 4.0, em 2012, o governo norte-americano criou o programa National Network of Manufacturing Innovation (atual Manufacturing USA) que visa inovação com um sistema de cogeração e transferência de tecnologia por meio de pesquisa, prototipagem, testes e desenvolvimento de tecnologia disruptiva. Com isenção fiscal de US\$ 80 bilhões aglutina empresas privadas, instituições públicas, universidades e institutos de pesquisa (ARBIX, et al., 2017). Para China, a chave é realizar contramedidas de atualização tecnológica para impulsionar a inovação, fortalecer a cooperação indústria-universidade-pesquisa-cliente, estabelecer projetos chaves, e principalmente, realizar pareamento tecnológico de última geração (FENG, ZHANG e ZHOU, 2018). Em 2015, o Japão estabeleceu o 
Industrial Value Chain Initiative (IVI) com o objetivo de rever a cadeia de valor industrial baseado em dois princípios: a) automação, habilidade humana e manufatura conectada para eliminar os desperdícios; b) abordagem pragmática que promove um modelo adaptável e colaborativo respeitando a cultura dos integrantes da cadeia. Trinta empresas japonesas, incluindo Mitsubishi Electric, Fujitsu, Nissan Motor e Panasonic, fazem parte da iniciativa (ZHONG, et al., 2017).

Para destacar sua importância, em 2016, a Indústria 4.0 foi a pauta do $46^{\circ}$ Fórum Econômico Mundial em Davos com o tema: Dominando a Quarta Revolução Industrial (Mastering the Fourth Industrial Revolution) (PFEIFFER, 2017).

Diversos sistemas, tecnologias e processos suportam o conceito da Indústria 4.0. Dentre um conjunto de possibilidades, é possível destacar:

- computação na nuvem (cloud computing) contém várias definições que transpassam o significado de computação virtual baseada na internet para desenvolver diferentes serviços por intermédio de recursos facilmente acessíveis (ZENG, ZHAO e LIU, 2012);

- sistemas colaborativos são ambientes de rede inteligentes em que humanos, organizações e dispositivos entrelaçados por sensores, atuadores e elementos computacionais interconectados, colaboram de forma transparente as suas funções (CAMARINHA-MATOS e AFSARMANESH, 2014);

- virtualização de ativos (virtualization ou digital twins) é uma tecnologia fundamental para o desenvolvimento da Indústria 4.0, pois fornece simulação do ambiente produtivo projetando os equipamentos e processos de acordo com os requisitos de negócio, e uma configuração de fábrica que atenda com dinamicidade as customizações de mercado (LU e XU, 2018);

- internet das coisas (internet of things - loT) torna possível conectar objetos, transferir dados sem a intervenção humana e a identificação entre equipamentos por intermédio da internet em convergência com a tecnologia sem fio (PUJARA e SATYANARAYANA, 2015);

- em função do alto volume, variedade e velocidade de dados gerados por controladores, sensores e sistemas na Indústria 4.0, há necessidade de coleta, integração, armazenamento, processamento e análise de dados, 
que em conjunto denominam o fenômeno Big Data Analytics (SANTOS, et al., 2017);

- sistemas ciber-físicos (Cyber-Physical Systems - CPS) são sistemas complexos que necessitam de especificações para o controle cronológico dos processos, modelagem de segurança, racionalização dos eventos contínuos para mapeamento e sequenciamento em eventos discretos (XU e ZHANG, 2013);

- mineração de dados (data mining) fornece a capacidade de interpretar grandes volumes de dados para basear a política de decisão por meio de acoplamento de banco de dados (clustering), pré-processamento, classificação, padrões e detecção de dados outliers (CALDERS e CUSTERS, 2013);

- protocolo de comunicação $A d-H o c$ por intermédio de redes sem fio e roteamento dinâmico (comutação periódica de pacotes) para evitar congestionamento de dados, garante integração máquina para máquina (machine to machine - M2M) para proporcionar medição descentralizada e em tempo real (YAN, et al., 2017);

- RFID (radio frequency identification) é uma classe tecnológica com transmissão de dados sem fio, que utiliza ondas de rádio para capturar as etiquetas (chip) sem obrigatoriedade de leitura ou intervenção para obtenção do dado (THAKARE, MUSALE e GANORKAR, 2008);

- Internet dos serviços (Internet of Services - loS) é caracterizada por grande número de serviços suportados por softwares distribuídos pela internet, requisitando novos padrões e arquiteturas de integração, bem como mecanismos flexíveis e dinâmicos de segurança de dados (AUTILI, GIANNAKOPOULOU e TIVOLI, 2018);

- disponibilidade dos dispositivos sensoriais desempenha papel de captura de dados de campo por meio de metodologias de controle confiáveis aplicadas em sensores de luz, sensores de força e telas de toque para informar o estado de máquinas e processos por intermédio de rede sem fio (ZHONG, et al., 2017). 
Com base na disponibilidade dessas tecnologias, Schuh et al. (2017) informam que o índice de implantação da Indústria 4.0 é medido em seis estágios de maturidade vinculados ao planejamento estratégico.

Ainda segundo Schuh et al. (2017) as empresas enfrentam, até então, desafios para desenvolver os requisitos básicos/fundamentais (estágios 1 e 2: informatização integrada e conectividade) para posteriormente suportar a implantação dos estágios avançados da Indústria 4.0: visibilidade, transparência, capacidade preditiva e adaptabilidade. A figura 1 apresenta $o$ relacionamento entre as fases do desenvolvimento da Indústria 4.0.

Figura 1 - Estágios para desenvolvimento da indústria 4.0

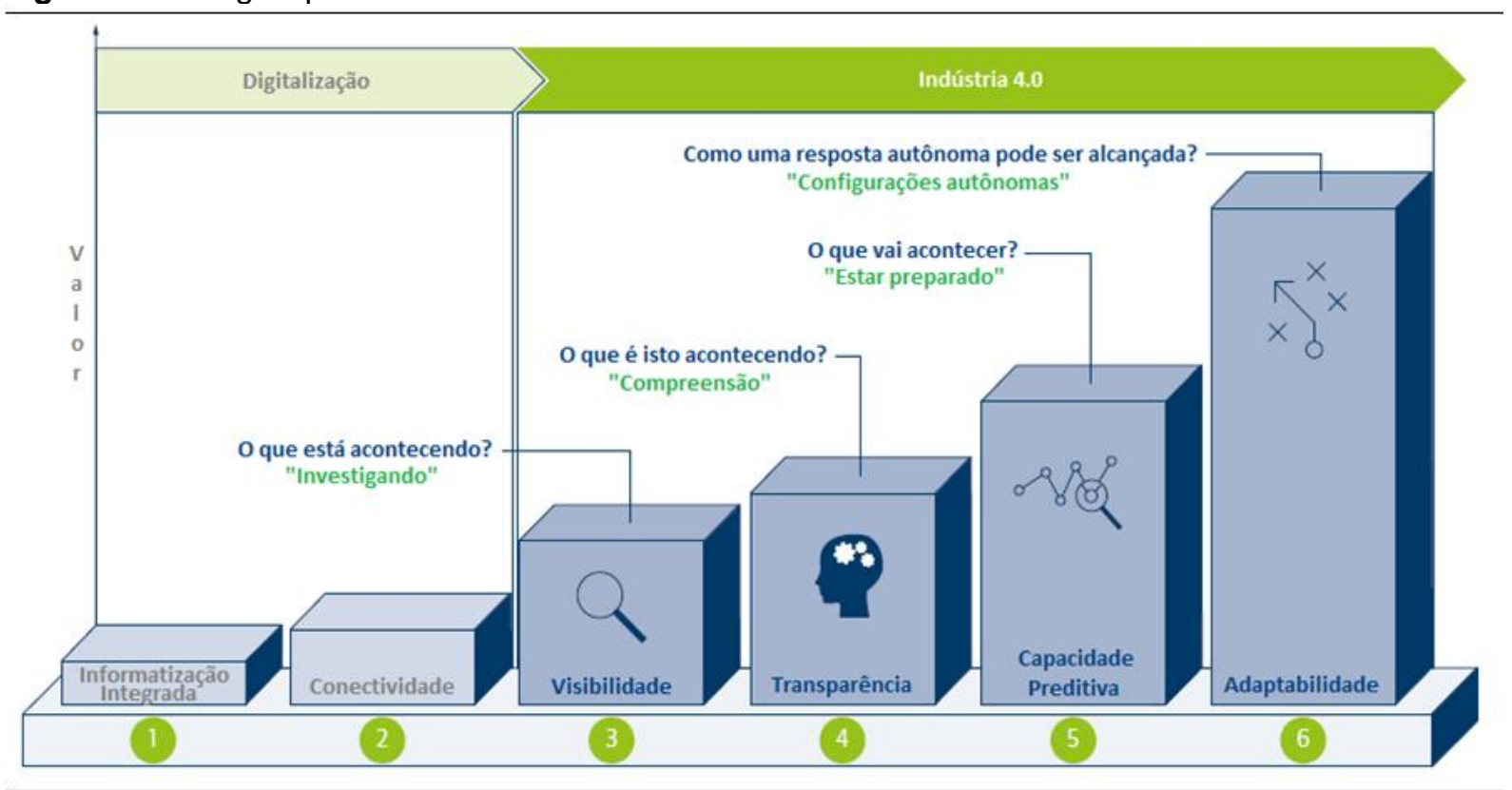

Fonte: adaptado de (SCHUH, et al., 2017)

Estágio 3 - Impulsionados pela redução dos custos, os dispositivos sensoriais conduzem o desenvolvimento do modelo digital, gerando visibilidade dos processos para suportar as decisões baseadas em dados de tempo real. Contudo, expõem uma quantidade elevada de informação que requer atenção na segurança dos dados (SCHUH, et al., 2017).

Estágio 4 - Os dados capturados devem gerar informações sobre as condições de equipamentos, processos em uso e necessidade de recursos, e desta forma, promover transparência, agilidade e contextualidade para tomada de decisão autônoma (SCHUH, et al., 2017). 
Estágio 5 - A capacidade preditiva está condicionada ao estágio de transparência (compreensão e integração de todo o sistema), possibilitando simular diferentes cenários para identificar em tempo hábil, medidas contingenciais que respondam aos eventos inesperados, e assim, produzam ações (ex: bypass) que permitam os componentes do sistema atingirem seus objetivos (SCHUH, et al., 2017).

Estágio 6 - Em função da variação dos dados de entrada (flutuação de mercado), as diversas tecnologias e processos necessitam ter adaptabilidade para proporcionar resposta autônoma. Entretanto, é necessário que os integrantes deste sistema compreendam a funcionalidade, capacidade e limitações envolvidas nessas tecnologias (SCHUH, et al., 2017).

\subsection{Cadeia de suprimentos da Indústria 4.0}

A conexão entre a variação da demanda e o planejamento estratégico tem lançado questões sobre os caminhos das organizações, direcionando investimentos em sistemas de manufatura integrados para responder em tempo real às mudanças $e$ prever melhores condições para a cadeia de suprimentos (CHIEN, DOU e FU, 2018).

A integração dos fornecedores requisitada pela Indústria 4.0 fornece previsibilidade, criando oportunidade para fornecimento com ganhos em escala e melhoria no atendimento dos recursos (PETRISOR e COZMIUC, 2017).

Uma empresa, dentro do conceito da cadeia de suprimento 4.0 (Supply Chain 4.0), é definida como um sistema que necessita integrar novas tecnologias e relacionamentos colaborativos entre outras empresas, equipamentos e usuários/operadores, visando produzir informação e previsibilidade aos demais integrantes (DOSSOU e NACHIDI, 2017).

A integração, como exemplo de relacionamento colaborativo, é uma maneira de redução da influência da variação da demanda e, consequentemente, redução dos impactos nos volumes dos estoques em cada nível da cadeia. A indústria 4.0 requisita avaliar alianças até os elos mais periféricos da tríade suprimentos / produção / cliente (NAGY, et al., 2018). A figura 2 apresenta um modelo de avaliação dos níveis de integração da cadeia de suprimentos. 
Figura 2 - Modelo de análise de integração dos níveis da cadeia de suprimento

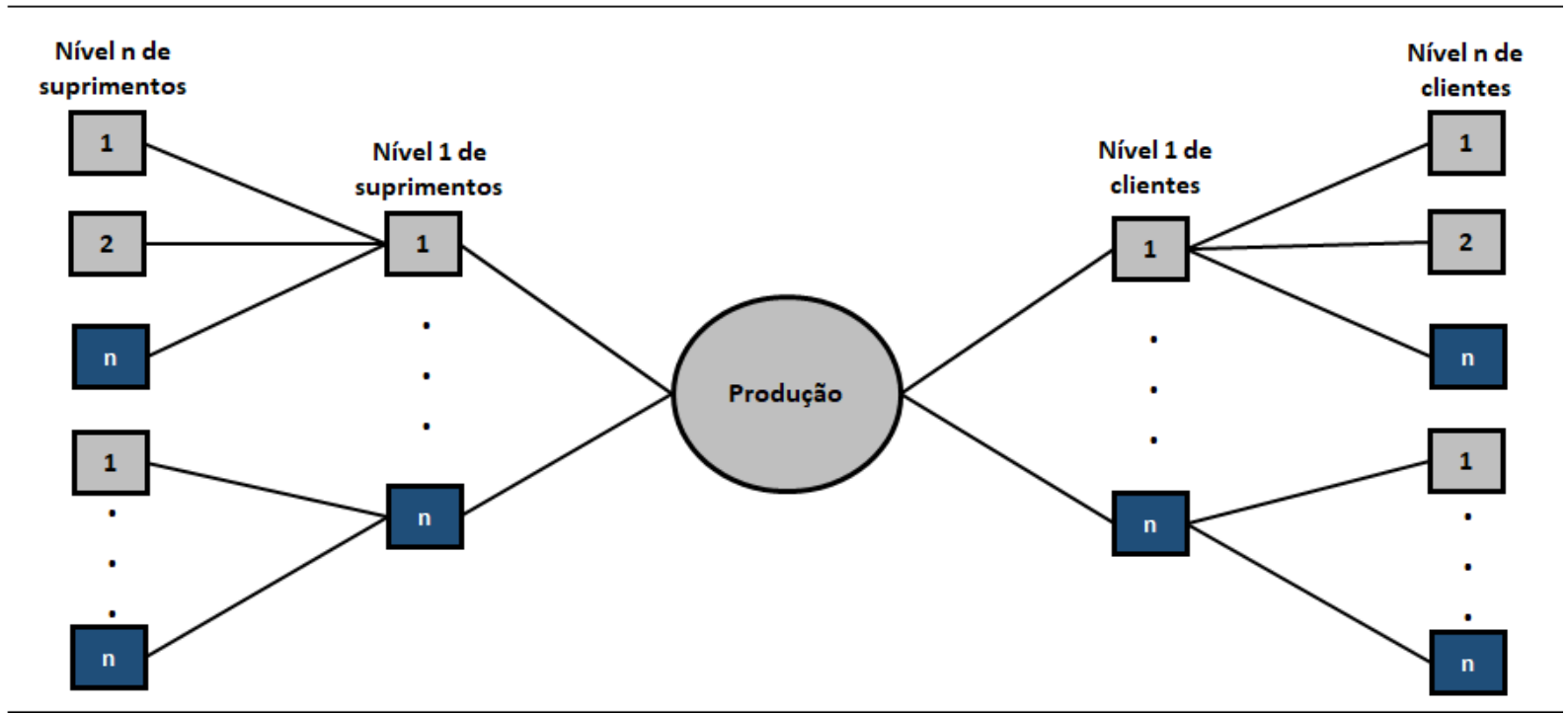

Fonte: adaptado de (NAGY, et al., 2018)

Para proporcionar colaboração, uma cadeia de suprimentos demanda relacionamento integrado dos múltiplos negócios (LAMBERT e COOPER, 2000). Desta forma, após analisar as possibilidades de integração é necessário desenvolver uma postura colaborativa.

A cadeia de suprimentos deve facilitar a execução de processos e promover a comunicação fluída entre seus componentes. Precisa compartilhar informações sobre os fatores intervenientes no relacionamento entre as empresas (características do mercado, documentos técnicos, informações operacionais, entre outros) e assim elevar o grau de confiança (PERKINS, et al., 2003).

Alguns exemplos práticos de medidas colaborativas na cadeia de suprimentos podem ser tomados como investimento em tecnologia para integrar o controle dos estoques em todos os elos da cadeia (VITORINO FILHO, et al., 2017).

Contudo, inicialmente é necessário avaliar o nível de colaboração emanado pelos elementos da cadeia de suprimentos. Para isso, uma empresa pode adotar uma forma sistémica (agrupamento de análises) observando os fatores que impactam na colaboração da relação (PERKINS, et al., 2003):

- questões sociais: desequilíbrio de poder, interesses não declarados, desconfiança e expectativas de conflitos; 
- questões externas: não exposição de processos críticos, nível de habilidade inadequado, comunicação pobre, danos ao relacionamento colaborativo e problemas de integridade dos dados;

- questões conjuntas: ações que promovem desconfiança, que limitam a colaboração e o suporte funcional interno;

- questões internas: mal entendimento sobre determinada circunstância, conflito de interesses.

A figura 4 apresenta um modelo para construção de um relacionamento colaborativo da cadeia de suprimentos com base no compartilhamento das informações para produzir conhecimento mútuo.

Figura 4 - Construção do relacionamento colaborativo da cadeia de suprimentos

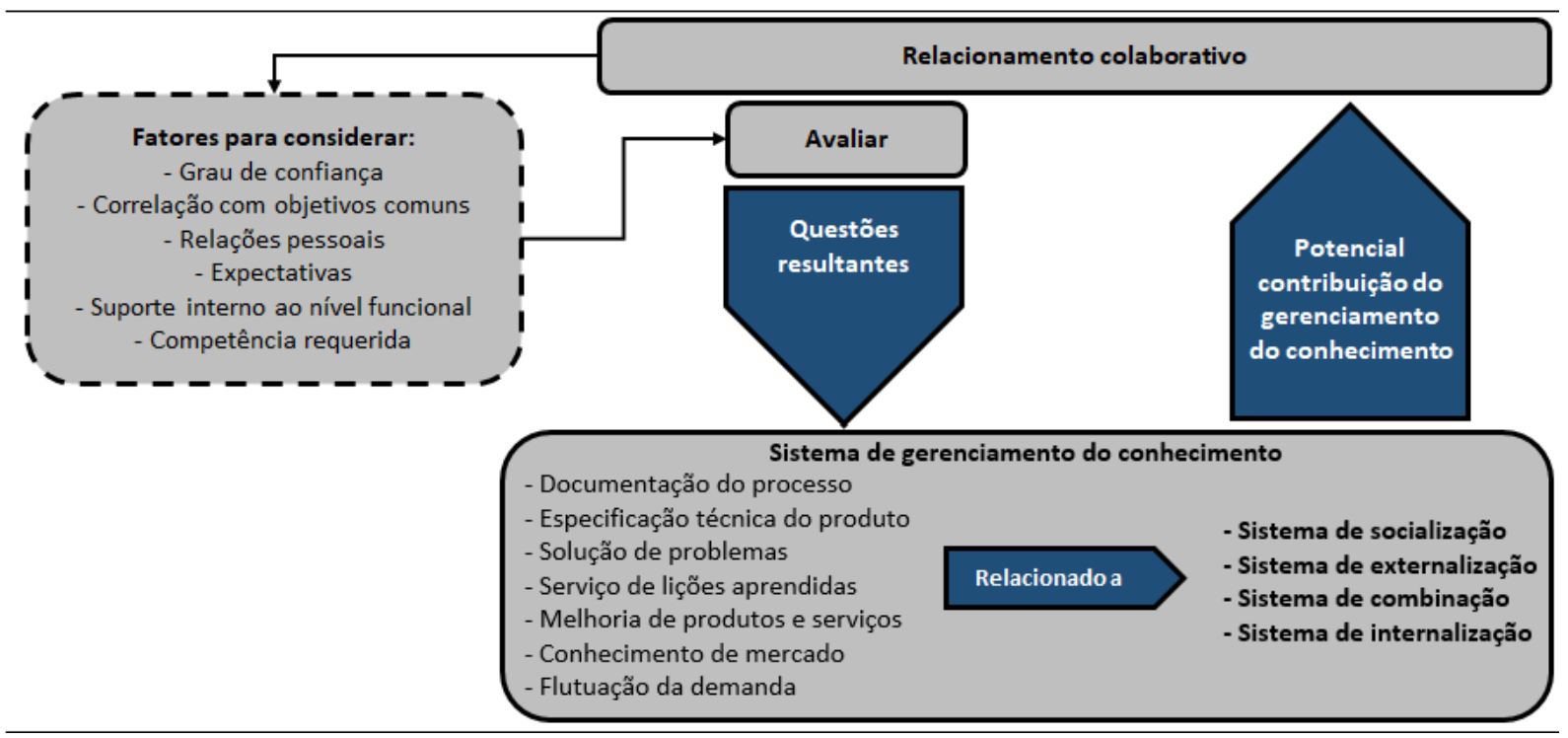

Fonte: adaptado de (PERKINS, et al., 2003)

Desse modo, para implantar uma cadeia de suprimentos colaborativa que atende a Indústria 4.0, fornecedores, fabricantes e clientes necessitam aumentar a transparência das informações, pois a interação dos relacionamentos é mais profunda. Tjahjono et al. (2017) recomendam atenção especial as áreas críticas operacionais que necessitam de clareza de dados: atendimento aos pedidos (recebimento, processamento e entrega) e logística de transporte.

Outro desafio na implementação de uma cadeia de suprimentos colaborativa é que necessita absorver conhecimento contínuo sobre os recursos e limitações das tecnologias envolvidas na Indústria 4.0 (ambientes de alta tecnologia). Uma alternativa 
adotada para fornecimento de soluções adequadas é a capacitação da equipe (SHAMIM, et al., 2016).

Outro ponto de atenção na implementação de uma cadeia de suprimentos colaborativa é que, a integração das tecnologias de fabricação inteligentes da Indústria 4.0 eleva a possibilidade de espionagem industrial. $O$ volume de dados transitados entre equipamentos e empresas aumenta, e o resultado desses ataques varia de dano econômico a perda de produção, requerendo medidas protetivas aos dados (TUPTUK e HAILES, 2018).

Por fim, como exemplo de medidas colaborativas, são apresentadas algumas práticas operacionais da cadeia de suprimentos utilizando recursos equivalentes aos da Indústria 4.0:

- ferramentas wireless, smart devices, RFID, GPS, cloud computing, loT têm características de mobilidade que podem suprir as necessidades da cadeia de suprimentos móvel (mobile supply chain management - mSCM) no fornecimento de soluções flexíveis que inter-relacionam processos, serviços e informação (BARATA, CUNHA e STAL, 2018);

- virtualização dos ativos ou digitalização é outro ponto que a Indústria 4.0 impacta à cadeia de suprimentos, pois as aquisições envoltas com estas tecnologias necessitam de decisões com viés estratégico, e assim, demandam habilidades específicas da equipe de compras e relacionamentos mais estreitos com fornecedores (BIENHAUS e HADDUD, 2018).

- internet das coisas (loT) também influencia as rotinas da cadeia de suprimentos, pois fornece recursos para redução de custos por meio da integração de dados, rastreamento do processo produtivo, transparência das decisões, precisão de inventário, visibilidade na seleção de fornecedores e descentralização do controle (BEN-DAYA, HASSINI e BAHROUN, 2017);

- ERP é um sistema de alto nível de gerenciamento da cadeia de suprimentos que coordena as interações entre cliente-fabricantefornecedor. Outro conceito da Indústria 4.0 que afeta a cadeia de suprimentos é projeto colaborativo C2NET (Cloud Collaborative Manufacturing Networks) que é desenvolvido para compartilhamento dos 
dados do ERP em sistemas na nuvem, permitindo a interação entre as diferentes organizações fora dos próprios ativos (QURESHI, et al., 2017);

- análise de dados suportada pelo Big Data Analytics fornece rápida capacidade de resposta às mudanças na demanda do mercado. Portanto, é uma solução atraente para a cadeia de suprimentos, em termos de melhoria do desempenho financeiro de uma organização (GOVINDAN, et al., 2018);

- RFID (radio frequency identification) possibilita identificação do mundo físico em larga escala (quantidade, localização, estado) permitindo que as indústrias façam uso desta tecnologia para fornecer comunicação das máquinas com seus processos como uma rede social. Desta forma, a cadeia de suprimentos recebe carga de informações operacionais atualizadas em tempo real para uma tomada de decisão mais completa (LOUW e WALKER, 2018);

- entre os esforços contidos na Indústria 4.0 para responder às mudanças de mercado, estão as ações da cadeia de suprimentos baseadas em sistemas computacionais na nuvem (processos virtualizados orientado a serviços) para realizar o planejamento, gestão da informação e o controle físico (RÖSCHINGER, KIPOURIDIS e GÜNTHNER, 2016).

- abordagem Lean Six Sigma é uma ferramenta para otimização dos processos operacionais aplicada na cadeia de suprimentos. A disponibilidade tecnológica da Indústria 4.0 (GPS, loT, RFID) ajuda no atendimento à demanda e gerenciamento da distância de entrega, evitando desperdícios e variações logísticas no controle do pedido (JAYARAM, 2016);

- filosofia just-in-time e just-in-sequence são utilizadas na Indústria 4.0 como ferramentas para suprir a flutuação da demanda quanto a disponibilização dos recursos. A cadeia de suprimentos faz uso dos mesmos conceitos para realizar a gestão de materiais (redução dos estoques) (BÁNYAI e BÁNYAI, 2017). 


\section{MÉTODO}

A metodologia deste artigo está dividida em duas seções. Uma análise bibliométrica foi desenvolvida na busca por referencial teórico que forneça exemplos de medidas colaborativas da cadeia de suprimentos para apoiar a Indústria 4.0. Posteriormente, foi elaborado um questionário autoaplicável junto a especialistas, na busca pela avaliação e classificação destas medidas utilizando o método AHP.

\subsection{Análise bibliométrica}

Foi desenvolvida uma revisão bibliométrica para identificar um padrão de publicação cientifica de forma apresentar amostragem de artigos relacionados ao interesse deste trabalho (MCBURNEY e NOVAK, 2002). A figura 5 apresenta os critérios de seleção utilizados na bibliometria para amostragem dos artigos.

Figura 5 - Estrutura para identificação dos artigos

$\begin{array}{lllllll}\begin{array}{c}\text { Critério de } \\ \text { seleção }\end{array} & \begin{array}{c}\text { Critério de } \\ \text { seleção }\end{array} & \text { Critério de } & \text { Critério de } \\ \text { seleção }\end{array}$

Fonte: desenvolvido pelo autor

Conforme critérios de seleção, cinco artigos foram analisados sobre a possiblidade de apresentarem exemplos de medidas colaborativas da cadeia de suprimentos apoiar a Indústria 4.0. O quadro 1 relaciona os artigos. 
Quadro 1 - Artigos selecionados conforme filtros da revisão bibliográfica

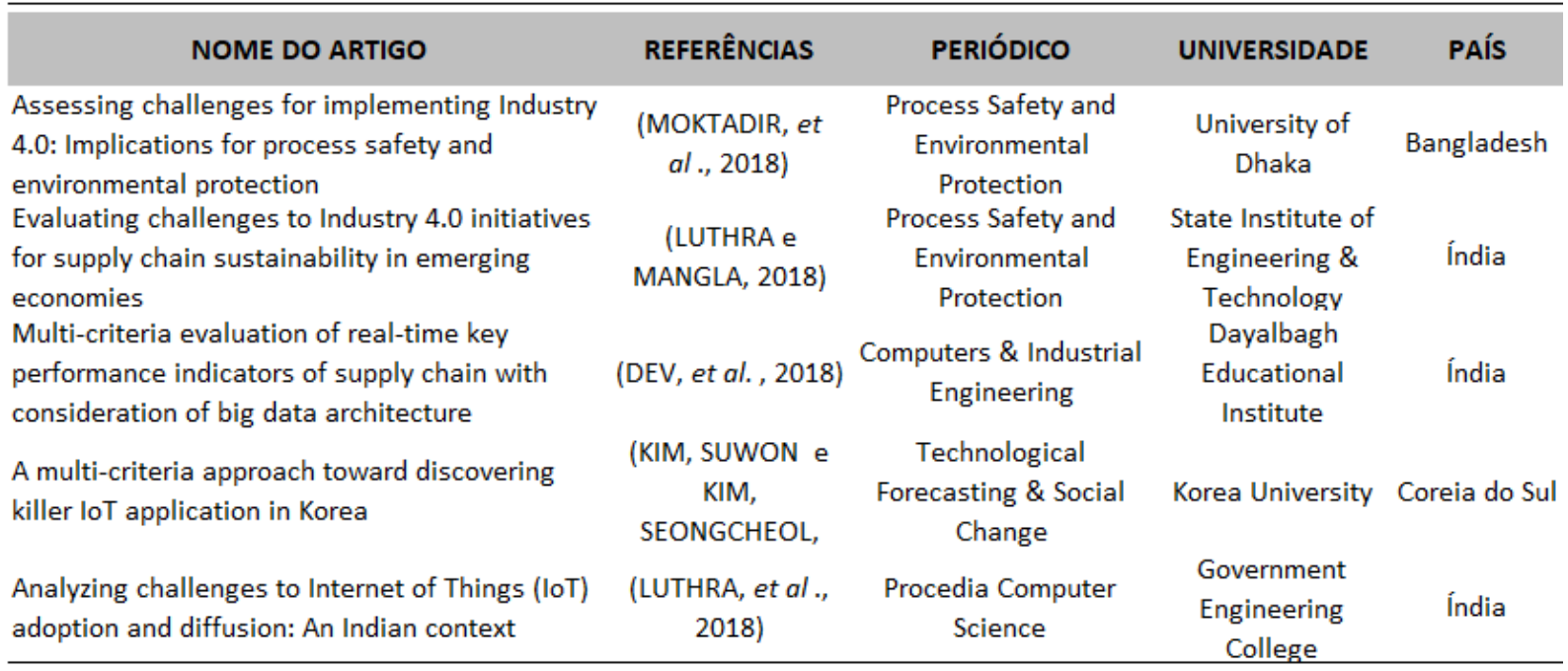

Fonte: desenvolvido pelo autor

Agora será necessário avaliar e classificar as alternativas colaborativas da cadeia de suprimentos para suportar a Indústria 4.0.

\subsection{AHP (Analytic Hierarchy Process)}

AHP é um método para estimar coeficientes de entrada-saída de um dado processo, baseado na comparação em pares de acordo com uma escala de priorização sem requerer um detalhamento extensivo para capturar a relação significante entre as alternativas (SAATY e VARGAS, 1979).

O AHP considera a subjetividade do julgamento humano (GANDHI, et al., 2016). Desta forma, pode ser adotado para avaliar critérios qualitativos.

Assim, respeitando os recursos do método AHP, é considerada a avaliação de especialistas para priorizar as medidas colaborativas da cadeia de suprimentos junto a Indústria 4.0 .

Para iniciar a avaliação, de acordo com os artigos amostrados, são identificados quatro critérios e oito alternativas para que possam ser avaliadas como ações da cadeia de suprimentos para colaborar com a quarta revolução industrial. Os quadros 2 e 3 apresentam, respectivamente, critérios e alternativas. 
Quadro 2 - Critérios da cadeia de suprimentos para suportar a Indústria 4.0

\begin{tabular}{ll}
\hline \multicolumn{1}{c}{ CRITÉRIOS } & \multicolumn{1}{c}{ BREVE DESCRIÇÃo } \\
Estratégico (ES) & $\begin{array}{l}\text { Representam obstáculos de nível estratégico para adotar aspectos políticos, } \\
\text { econômicos e culturais aplicados na cadeia de suprimentos para suportar a } \\
\text { Indústria 4.0. } \\
\text { Representam obstáculos de nível organizacional para adotar aspectos } \\
\text { conceituais, financeiros e gestão do negócio aplicados na cadeia de suprimentos } \\
\text { prganizacional (OR) }\end{array}$ \\
Tecnológico (TE) & $\begin{array}{l}\text { Representam obstáculos de nível tecnológico para adotar aspectos de } \\
\text { comunicação, integração sistêmica e qualidade de dados relacionados a cadeia } \\
\text { de suprimentos para suportar a Indústria 4.0. }\end{array}$ \\
Questỗes Legais e & $\begin{array}{l}\text { Representam obstáculos legais e de segurança da informação para implementar } \\
\text { proteção da informação, ações de comunicação transparentes e processos } \\
\text { Segurança da } \\
\text { Informação (LS) }\end{array}$ \\
\hline
\end{tabular}

Fonte: adaptado de (LUTHRA e MANGLA, 2018)

Para auxiliar na classificação das alternativas são utilizadas avaliações de posições de liderança de empresas em diversos segmentos. Um conjunto de dez especialistas é convidado para responder um questionário autoaplicável disponibilizado eletronicamente. Os profissionais selecionados são escolhidos devido ao alto nível de qualificação em suas áreas dentro da indústria e em atividades da cadeia de suprimentos. Vivência em posições de gestão, este grupo é formado $90 \%$ por diretores, gerentes e coordenadores, com formação acadêmica nas áreas de engenharia e administração de empresas. A maioria dos escolhidos tem mais de 10 anos de experiência profissional conforme demonstrado na figura 6 .

Figura 6 - Informações sobre os integrantes da pesquisa

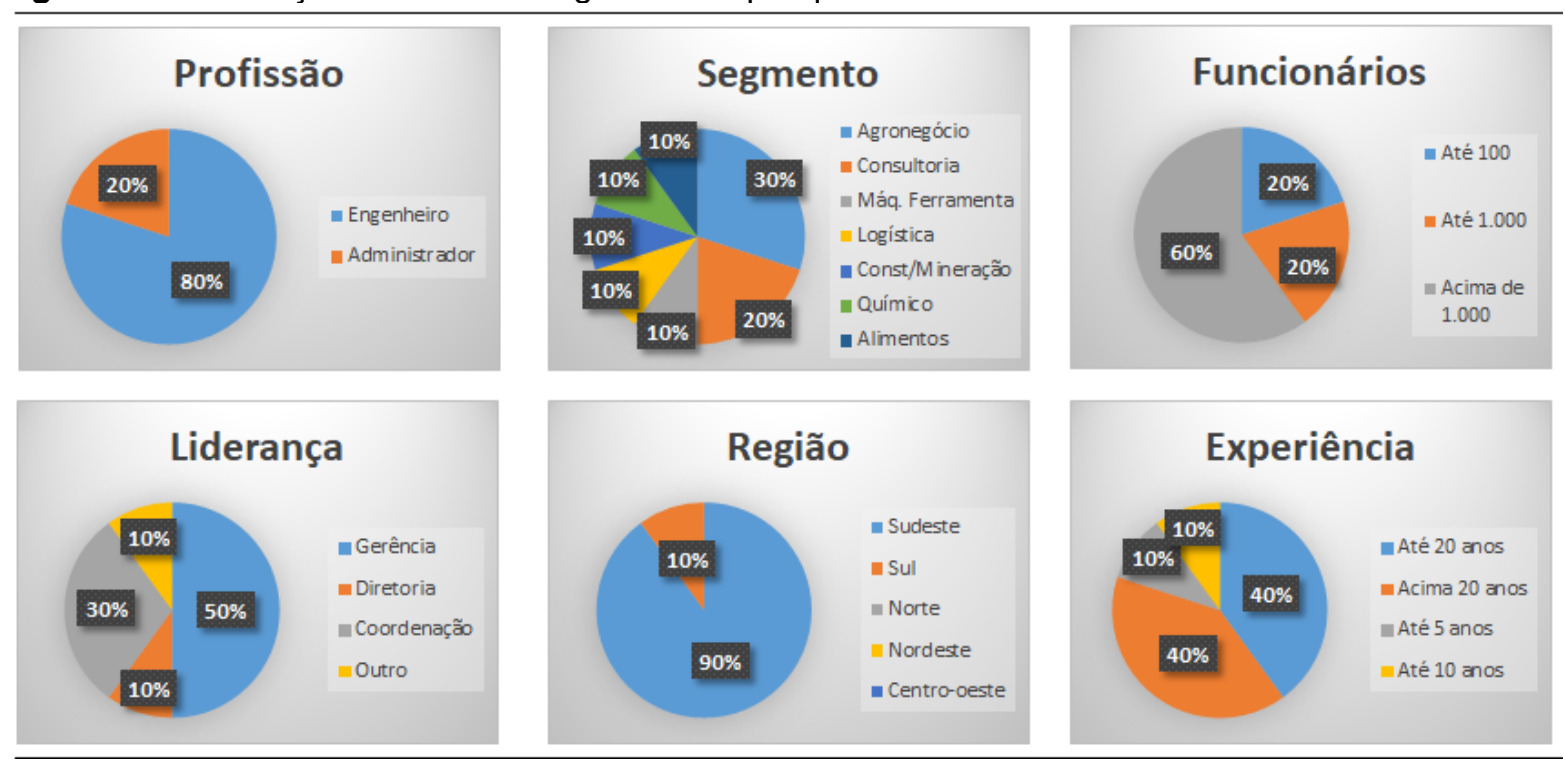

Fonte: desenvolvido pelo autor 
Quadro 3 - Alternativas colaborativas da cadeia de suprimentos para suportar a indústria 4.0

\begin{tabular}{|c|c|c|}
\hline ALTERNATIVAS & REFERÊNCIAS & BREVE DESCRIÇÃO \\
\hline $\begin{array}{l}\text { Falta de cultura } \\
\text { digital e baixa clareza } \\
\text { sobre os benefícios } \\
\text { dos investimentos } \\
\text { (ES1). }\end{array}$ & $\begin{array}{l}\text { (KIEL, et al. , 2017); } \\
\text { (MARQUES, et al. , } \\
\text { 2017); (RAS, et al., } \\
\text { 2017); (SCHUH, et al., } \\
\text { 2017). }\end{array}$ & $\begin{array}{l}\text { A digitalização é um dos principais fatores para iniciar a Indústria 4.0. A } \\
\text { digitalização requer da cadeia de suprimentos conhecer as tecnologias } \\
\text { de comunicação na entrada ou saída dos dados com empresas da } \\
\text { Indústria 4.0. Para isso, é prudente analisar os benefícios e o retorno } \\
\text { destes investimentos. }\end{array}$ \\
\hline $\begin{array}{l}\text { Falta de políticas } \\
\text { governamentais } \\
\text { (ES2). }\end{array}$ & $\begin{array}{l}\text { (BRICS BUSINESS } \\
\text { COUNCIL, 2018). }\end{array}$ & $\begin{array}{l}\text { Políticas governamentais são cruciais para o desenvolvimento da } \\
\text { Indústria 4.0. A falta de diretrizes do governo retarda a maioria } \\
\text { iniciativas. São necessárias medidas das empresas da cadeia de } \\
\text { suprimentos para desenvolver políticas públicas que transformem } \\
\text { funções tradicionais em processos mais adequados à Indústria } 4.0 \text {. }\end{array}$ \\
\hline $\begin{array}{l}\text { Restrições } \\
\text { financeiras } \\
\text { orçamentária e baixo } \\
\text { suporte à gestão } \\
\text { (OR1). }\end{array}$ & $\begin{array}{l}\text { (THEORIN, et al., } \\
\text { 2017); (NICOLETTI, } \\
\text { 2018); (GÖKALP, SENER } \\
\text { e EREN, 2017); } \\
\text { (SAVTSCHENKO, } \\
\text { SCHULTE e VOB, 2017); } \\
\text { (SHAMIM. et al.. 2017). }\end{array}$ & $\begin{array}{l}\text { Equipamentos, máquinas avançadas, instalações, sistemas e inovações } \\
\text { de processos são requisitos da Indústria } 4.0 \text { que geram mudanças na } \\
\text { gestão do negócio. É necessário que as empresas da cadeia de } \\
\text { suprimentos tomem medidas para priorizar o orçamento visando } \\
\text { desenvolver a capacidade de seus processos, melhores práticas de } \\
\text { gestão para fornecer soluções adequadas e acompanhar a Indústria } 4.0 \text {. }\end{array}$ \\
\hline $\begin{array}{l}\text { Baixo entendimento } \\
\text { sobre as implicações } \\
\text { da Indústria } 4.0 \\
\text { (OR2). }\end{array}$ & $\begin{array}{c}\text { (ALMADA-LOBO, 2015); } \\
\text { (HOFMANN e RÜSCH, } \\
\text { 2017). }\end{array}$ & $\begin{array}{l}\text { Existe baixo entendimento sobre as implicações da Indústria } 4.0 \text { entre os } \\
\text { pesquisadores e praticantes. São necessárias medidas para } \\
\text { compreensão e capacitação das empresas da cadeia de suprimentos } \\
\text { sobre a importância da Indústria } 4.0 \text {, e assim reduzir a insegurança } \\
\text { sobre os impactos na relacão entre seus participantes. }\end{array}$ \\
\hline $\begin{array}{l}\text { Falta de integração } \\
\text { tecnológica e padrões }\end{array}$ & & $\begin{array}{l}\text { A integração tecnológica e comunicação são essenciais para os } \\
\text { resultados da Indústria 4.0. É necessário medida de integração sistêmica }\end{array}$ \\
\hline $\begin{array}{l}\text { lo para } \\
\text { amento de } \\
\text { l). }\end{array}$ & $\begin{array}{l}\text { L., 2015); (BRANKE, } \\
\text { FARID e SHAH, 2016). }\end{array}$ & os vários componentes heterogêneo \\
\hline $\begin{array}{l}\text { Baixa qualidade dos } \\
\text { dados existentes } \\
\text { (TE2). }\end{array}$ & (SANTOS, $e$ & $\begin{array}{l}\text { A qualidade dos dados é um dos principais requisitos na Indústria 4.0. } \\
\text { Máquinas, sensores e sistemas estão interconectados gerando e } \\
\text { solicitando dados. As empresas da cadeia de suprimentos necessitam } \\
\text { tomar medidas que garantam integridade das informações antes da sua } \\
\text { aplicação na tomada de decisão. }\end{array}$ \\
\hline $\begin{array}{l}\text { Questões de } \\
\text { segurança e aspectos } \\
\text { legais (LS1). }\end{array}$ & $\begin{array}{l}\text { (SOMMER, 2015); } \\
\text { (WANG, et al. , 2016); } \\
\text { (PEREIRA, BARRETO e } \\
\text { AMARAL, 2017); } \\
\text { (MÜLLER, DOTZAUER e } \\
\text { VOIGT, 2017). } \\
\text { (LEE, KAO e YANG, }\end{array}$ & $\begin{array}{l}\text { Um dos requisitos da Indústria } 4.0 \text { é a conexão entre diversas } \\
\text { organizações, máquinas e processos via internet. Para reduzir } \\
\text { vulnerabilidade dos sistemas, é necessário que as empresas da cadeia } \\
\text { de suprimentos adotem medidas contra invasores para o roubo de } \\
\text { credenciais privilegiadas e exposição de dados em massa da empresa, } \\
\text { bem como medidas de suporte às questões jurídicas envolvidas. }\end{array}$ \\
\hline $\begin{array}{l}\text { de } \\
\text { ção (LS2). }\end{array}$ & $\begin{array}{l}\text { 2014); (DUARTE e CRUZ- } \\
\text { MACHADO, 2017); } \\
\text { (PFOHL, YAHSI e } \\
\text { KURNAZ, 2017). }\end{array}$ & $\begin{array}{l}\text { E importante compreender as políticas organizacionais para possibilitar } \\
\text { a implantação dos conceitos da Indústria } 4.0 \text {. São necessárias medidas } \\
\text { das empresas da cadeia de suprimentos que proporcionem } \\
\text { transparência e compatibilidade na comunicação com a Indústria } 4.0 \text {. }\end{array}$ \\
\hline
\end{tabular}

Fonte: adaptado de (LUTHRA e MANGLA, 2018)

Com base nas avaliações dos especialistas, é determinante estruturar hierarquicamente os critérios e alternativas colaborativas da cadeia de suprimentos. A hierarquia utilizada no método AHP é definida em três níveis: (nível 1) - priorizar iniciativas colaborativas na cadeia de suprimentos para implantação da Indústria 4.0; (nível 2) - os quatro critérios: Estratégico (ES), Organizacional (OR), Tecnológico (TE) 
e Questões Legais e Segurança da Informação (LS); e (nível 3) - oito medidas colaborativas agrupadas por similaridade. A figura 7 apresenta a hierarquia das medidas colaborativas da cadeia de suprimentos junto à Indústria 4.0.

Figura 7 - Hierarquia dos critérios e alternativas colaborativas da cadeia de suprimentos

Priorizar iniciativas colaborativas na cadeia de suprimentos para implantação da Indústria 4.0

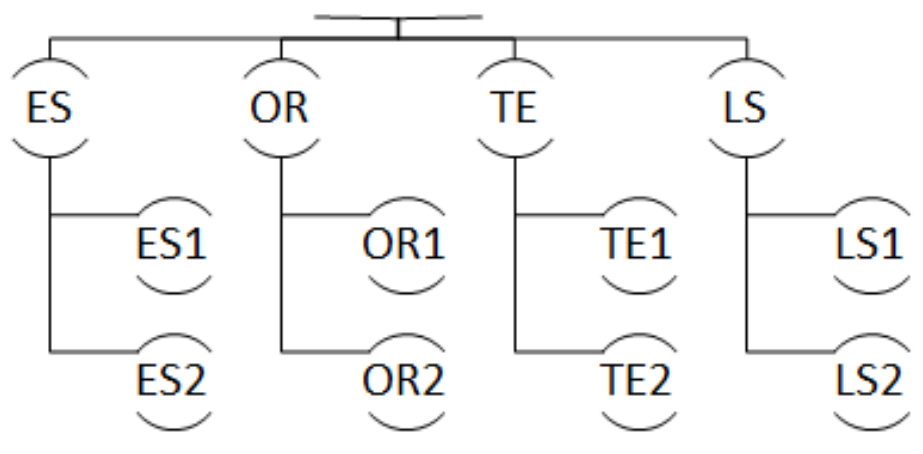

Fonte: desenvolvido pelo autor

\section{RESULTADOS}

O método Analytic Hierarchy Process (AHP) é aplicado para priorizar as iniciativas colaborativas na cadeia de suprimentos para implantação dos conceitos da Indústria 4.0 acatando os critérios e alternativas levantados da revisão teórica. A condução metodológica é desenvolvida em sete passos.

No PASSO 1 são analisados os critérios de seleção por intermédio de uma matriz recíproca para comparação em pares com base na escala fundamental ou escala de importância relativa de Thomas L. Saaty (SAATY e VARGAS, 1979). O resultado da vivência dos profissionais pesquisados é apresentado na tabela 1.

Tabela 1 - Matriz recíproca entre critérios

\begin{tabular}{|c|c|c|c|c|}
\hline Critérios & ES & OR & TE & LS \\
\hline ES & 1 & 5 & 5 & 4 \\
\hline OG & $1 / 5$ & 1 & 2 & $1 / 2$ \\
\hline TE & $1 / 5$ & $1 / 2$ & 1 & 2 \\
\hline LS & $1 / 4$ & 2 & $1 / 2$ & 18 \\
\hline
\end{tabular}

Fonte: desenvolvido pelo autor 
Com base na tabela de comparação recíproca, no PASSO 2 é realizada a média geométrica (auto vetor). O cálculo da média geométrica de um conjunto de números positivos é definido como o produto de todos os membros do conjunto elevado ao inverso da quantidade de membros. Cálculos na tabela 2.

Tabela 2 - Média geométrica dos critérios

\begin{tabular}{|c|c|c|c|c|c|}
\hline Critérios & ES & OR & TE & LS & Média Geométrica (auto vetor) \\
\hline ES & 3 & 5,0000 & 5,0000 & 4,0000 & 3,1623 \\
\hline OG & 0,2000 & $1 \%$ & 2,0000 & 0,5000 & 0,6687 \\
\hline TE & 0,2000 & 0,5000 & 1 & 2,0000 & 0,6687 \\
\hline LS & 0,2500 & 2,0000 & 0,5000 & 1 & 0,7071 \\
\hline Soma & 1,6500 & 8,5000 & 8,5000 & 7,5000 & 5,2069 \\
\hline
\end{tabular}

Fonte: desenvolvido pelo autor

No PASSO 3 são informados os pesos ( 1 a 10) de cada alternativa por meio da inferência dos profissionais e detalhada a especificação de cada critério (QMM quanto maior melhor ou qqm - quanto menor melhor). Resultados na tabela 3.

Tabela 3 - Peso das alternativas

\begin{tabular}{ccccc}
\hline Alternativas & ES & OR & TE & LS \\
ES1 & 9 & 7 & 9 & 4 \\
ES2 & 9 & 4 & 4 & 8 \\
OR1 & 8 & 9 & 7 & 7 \\
OR2 & 8 & 8 & 8 & 6 \\
TE1 & 5 & 8 & 9 & 8 \\
TE2 & 7 & 7 & 9 & 8 \\
LS1 & 8 & 7 & 7 & 9 \\
LS2 & 9 & 8 & 6 & 5 \\
Especificação & QMM & QMM & QMM & QMM \\
\hline
\end{tabular}

Fonte: desenvolvido pelo autor

Posteriormente, é calculada a normalização e transposição dos critérios no PASSO 4. A normalização é realizada pela representatividade do auto vetor e a transposição é obtida do somatório dos critérios. A tabela 4 apresenta os resultados.

No PASSO 5 é avaliada a relação de consistência dos critérios adotados pelos profissionais. Considera-se coerente o valor de CR (razão de consistência) menor que $10 \%$. 
Para calcular o CR, inicialmente deve-se obter o autovalor, que é calculado pelo produto entre a coluna normalizada e transposta dos critérios. O somatório dos autovalores resulta no lambda máximo ( $\lambda$ max). A tabela 5 apresenta os resultados.

Tabela 4 - Normalização e transposição dos critérios

\begin{tabular}{cccc}
\hline Critérios & Média Geométrica (auto vetor) & Normalização & Transposição \\
ES & 3,1623 & $61 \%$ & 1,6500 \\
OR & 0,6687 & $13 \%$ & 8,5000 \\
TE & 0,6687 & $13 \%$ & 8,5000 \\
LS & 0,7071 & $14 \%$ & 7,5000 \\
Soma & 5,2069 & $100 \%$ & - \\
\hline
\end{tabular}

Fonte: desenvolvido pelo autor

Tabela 5 - Autovalor e valor de lambda máximo

\begin{tabular}{cccc}
\hline Critérios & Normalização & Transposição & Autovalor \\
ES & $61 \%$ & 1,6500 & 1,0021 \\
OR & $13 \%$ & 8,5000 & 1,0917 \\
TE & $13 \%$ & 8,5000 & 1,0917 \\
LS & $14 \%$ & 7,5000 & 1,0185 \\
& Soma ( $\lambda_{\text {max }}$ & & 4,2040 \\
\hline
\end{tabular}

Fonte: desenvolvido pelo autor

Com o valor do $\lambda$ max em conjunto com a quantidade de critérios "n" é obtido o valor de $\mathrm{Cl}$ (índice de coerência). A fórmula 1 apresenta os cálculos e o resultado para Cl.

Fórmula 1 - Cálculos para obtenção do Cl

$$
C I=\frac{\lambda \max -\mathrm{n}}{\mathrm{n}-1}=\frac{4,2040-4}{4-1}=0,0680
$$

Fonte: adaptado de Saaty e Vargas, (1979)

A tabela 6 apresenta os valores do índice randômico (Random Index - RI) para cada número de critério. O valor definido é utilizado para calcular o $\mathrm{CR}$. 
Tabela 6 - Índice randômico (RI)

\begin{tabular}{lllccccccccccc}
\hline Qtd de critério & $\mathbf{1}$ & $\mathbf{2}$ & $\mathbf{3}$ & $\mathbf{4}$ & $\mathbf{5}$ & $\mathbf{6}$ & $\mathbf{7}$ & $\mathbf{8}$ & $\mathbf{9}$ & $\mathbf{1 0}$ & $\mathbf{1 1}$ & $\mathbf{1 2}$ \\
RI & 0 & 0 & 0,58 & 0,9 & $\mathbf{1 , 1 2}$ & $\mathbf{1 , 2 4}$ & $\mathbf{1 , 3 2}$ & $\mathbf{1 , 4 1}$ & $\mathbf{1 , 4 5}$ & $\mathbf{1 , 4 9}$ & $\mathbf{1 , 5 1}$ & $\mathbf{1 , 4 8}$
\end{tabular}

Fonte: adaptado de Saaty e Vargas, (1979)

A fórmula 2 apresenta o cálculo e resultado para obtenção do CR que é a razão entre o $\mathrm{Cl}$ e o RI.

Fórmula 2 - Cálculos para obtenção do CR (razão de consistência)

$$
C R=\frac{C I}{R I}=\frac{0,0680}{0,9}=8 \%
$$

Fonte: adaptado de Saaty e Vargas, (1979)

Portanto, como o valor de CR é menor que $10 \%$, os posicionamentos adotados pelos profissionais na matriz recíproca podem ser aceitos.

No PASSO 6 os critérios diretos (QMM) são normalizados pelo cálculo da representatividade dos valores individuais no total. A tabela 7 tem os resultados.

Tabela 7 - Normalização dos critérios

\begin{tabular}{ccccccccc}
\hline Alternativas & ES & $\%$ & OR & $\%$ & TE & $\%$ & LS & $\%$ \\
ES1 & 9 & $14 \%$ & 7 & $12 \%$ & 9 & $15 \%$ & 4 & $7 \%$ \\
ES2 & 9 & $14 \%$ & 4 & $7 \%$ & 4 & $7 \%$ & 8 & $15 \%$ \\
OR1 & 8 & $13 \%$ & 9 & $16 \%$ & 7 & $12 \%$ & 7 & $13 \%$ \\
OR2 & 8 & $13 \%$ & 8 & $14 \%$ & 8 & $14 \%$ & 6 & $11 \%$ \\
TE1 & 5 & $8 \%$ & 8 & $14 \%$ & 9 & $15 \%$ & 8 & $15 \%$ \\
TE2 & 7 & $11 \%$ & 7 & $12 \%$ & 9 & $15 \%$ & 8 & $15 \%$ \\
LS1 & 8 & $13 \%$ & 7 & $12 \%$ & 7 & $12 \%$ & 9 & $16 \%$ \\
LS2 & 9 & $14 \%$ & 8 & $14 \%$ & 6 & $10 \%$ & 5 & $9 \%$ \\
Total & 63 & $100 \%$ & 58 & $100 \%$ & 59 & $100 \%$ & 55 & $100 \%$ \\
\hline
\end{tabular}

Fonte: desenvolvido pelo autor

A sumarização é realizada no PASSO 7 onde é desenvolvido o vetor decisão por intermédio do somatório do produto entre a normalização de cada alternativa e a normalização do auto vetor.

As medidas colaborativas classificadas como prioritárias pelos especialistas são originárias de questões que envolvem: 
- Falta de cultura digital e baixa clareza sobre os benefícios dos investimentos (ES1);

- Questões de segurança e aspectos legais (LS1);

- Problemas de comunicação (LS2).

A tabela 8 apresenta os resultados classificados de todas as alternativas avaliadas pelos especialistas.

Tabela 8 - Vetor decisão dos critérios

\begin{tabular}{|c|c|c|c|c|c|c|}
\hline Alternativas & Classificação & ES & OR & TE & LS & Vetor decisão \\
\hline ES1 & $1 \underline{a}$ & $14 \%$ & $12 \%$ & $15 \%$ & $7 \%$ & $13,17 \%$ \\
\hline LS1 & $2^{\mathrm{a}}$ & $13 \%$ & $12 \%$ & $12 \%$ & $16 \%$ & $13,01 \%$ \\
\hline LS2 & $3 \underline{a}$ & $14 \%$ & $14 \%$ & $10 \%$ & $9 \%$ & $12,99 \%$ \\
\hline OR1 & $4 a$ & $13 \%$ & $16 \%$ & $12 \%$ & $13 \%$ & $12,96 \%$ \\
\hline OR2 & 5 & $13 \%$ & $14 \%$ & $14 \%$ & $11 \%$ & $12,71 \%$ \\
\hline ES2 & $6 a$ & $14 \%$ & $7 \%$ & $7 \%$ & $15 \%$ & $12,41 \%$ \\
\hline TE2 & $7 \underline{a}$ & $11 \%$ & $12 \%$ & $15 \%$ & $15 \%$ & $12,23 \%$ \\
\hline TE1 & $8 \mathrm{a}$ & $8 \%$ & $14 \%$ & $15 \%$ & $15 \%$ & $10,53 \%$ \\
\hline \multicolumn{2}{|c|}{ Normalização do auto vetor } & $61 \%$ & $13 \%$ & $13 \%$ & $14 \%$ & - \\
\hline
\end{tabular}

Fonte: desenvolvido pelo autor

Desta forma, como resultado deste estudo que visa responder à questão de pesquisa, a cadeia de suprimentos poder colaborar com a Indústria 4.0 implementando esforços para conhecer profundamente as tecnologias aplicadas na Indústria 4.0, e com isso, acompanhar os requisitos solicitados com maior propriedade. Para conhecer de perto estes avanços tecnológicos, sugere-se fazer uma análise econômica sobre o retorno que estes investimentos podem proporcionar ao negócio.

Bem como, em razão do maior volume de dados transitados pela Indústria 4.0, a cadeia de suprimentos pode colaborar investindo em tecnologia de segurança da informação, evitando acesso inapropriado ao conteúdo técnico e proporcionando confiabilidade aos elementos da cadeia. Pode também reivindicar medidas legais protetivas que resultem na proteção contra a espionagem industrial.

Da mesma maneira, a cadeia de suprimentos pode colaborar gerando maior transparência e comunicação no relacionamento com a Indústria 4.0. Para isso, é sugerido compartilhar informações operacionais, características de mercado e 
documentos técnicos que possam elevar o grau de confiança da relação, em função do envolvimento mais profundo entre as empresas.

\section{CONCLUSÃO}

A disponibilidade tecnológica que está permitindo o desenvolvimento dos conceitos da Indústria 4.0, é a mesma que requer medidas colaborativas da cadeia de suprimentos para apoiar a concretização dos resultados projetados com a quarta revolução industrial.

Para isso, a cadeia de suprimentos, que o vetor de suporte dos recursos produtivos, necessita antever questões em seus processos que proporcionem flexibilidade de ressuprimento, controle descentralizado em larga escala e tomada de decisão autônoma.

Desta maneira, para que possa atender o ritmo da Indústria 4.0 de forma integrada, são requeridas medidas colaborativas à cadeia de suprimentos no tocante a compreensão sobre as peculiaridades tecnológicas, segurança da informação e iniciativas que provoquem transparência no relacionamento.

Com isso, é uma questão de tempo para haver uma remodelação na forma de fazer da cadeia de suprimentos, pois a combinação da modificação das características de consumo (customização em massa) com as tecnologias disponíveis na Indústria 4.0, tem natureza imperativa o suficiente para determinar caminhos aos fornecedores de recursos.

Assim, aparenta ser mais sensato para cadeia de suprimentos facear tais mudanças com um viés colaborativo, do que no futuro, ser surpreendida compulsoriamente.

\section{REFERÊNCIAS}

ALMADA-LOBO, F.; The Industry 4.0 Revolution And The Future Of Manufacturing Execution Systems (MES). Journal of Innovation Management. v. 3, n. 4, p. 16-21, 2015. https://doi.org/10.24840/2183-0606 003.004 0003

ARBIX, G.; SALERNO, M. S.; ZANCUL, E.; AMARAL, G.; LINS, L. M.; Advanced Manufacturing: What Is to Be Learnt from Germany, the U. S., and China. CEBRAP. v. 36, n. 3, nov. 2017. https://doi.org/10.25091/S01013300201700030003

AUTILI, M.; GIANNAKOPOULOU, D.; TIVOLI, M.; Thematic Series on Verification and Composition for the Internet of Services and Things. Journal of Internet Services and 
Applications. v. 9, n. 1, Article number 10, dec. 2018. https://doi.org/10.1186/s13174-018$\underline{0080-9}$

BÁNYAI, T.; BÁNYAI, A.; Modelling Of Just-In-Sequence Supply Of Manufacturing Processes. MATEC Web of Conferences. v. 112, Article number 06025, jul. 2017. https://doi.org/10.1051/matecconf/201711206025

BARATA, J.; CUNHA, P. R.; STAL, J.; Mobile Supply Chain Management In The Industry 4.0 Era: An Annotated Bibliography And Guide For Future Research. Journal of Enterprise Information Management. v. 31, n. 1, p. 173-192, 2018. https://doi.org/10.1108/JEIM-09$\underline{2016-0156}$

BAUER, H.; SCHOONMANN, A.; REINHART, G.; Approach For Model-Based Change Impact Analysis In Factory Systems. IEEE International Symposium on Systems Engineering. Article number 8088301, out. 2017. https://doi.org/10.1109/SysEng.2017.8088301

BEN-DAYA, M.; HASSINI, E.; BAHROUN, Z.; Internet Of Things And Supply Chain Management: A Literature Review. International Journal of Production Research. p. 1-24, nov. 2017. https://doi.org/10.1080/00207543.2017.1402140

BIENHAUS, F.; HADDUD, A.; Procurement 4.0: Factors Influencing The Digitisation Of Procurement And Supply Chains. Business Process Management Journal. maio 2018. https://doi.org/10.1108/BPMJ-06-2017-0139

BMBF (BUNDESMINISTERIUM FÜR BILDUNG UND FORSCHUNG). Digitale Wirtschaft und Gesellschaft - Industrie 4.0. Disponível em: https://www.bmbf.de/de/zukunftsprojektindustrie-4-0-848.html. Acesso em: 15 jun. 2018.

BONAVOLONTA, F.; TEDESCO, A.; MORIELLO, R. S. L.; TUFANO, A.; Enabling Wireless Technologies For Industry 4.0: State Of The Art. IEEE International Workshop on Measurement and Networking. Article number 8078381, out. 2017. https://doi.org/10.1109/IWMN.2017.8078381

BRANKE, J.; FARID, S. S.; SHAH, N.; Industry 4.0: A Vision For Personalized Medicine Supply Chains? Cell \& Gene Therapy. p. 263-270, 2016.

https://doi.org/10.18609/cgti.2016.027

BRICS BUSINESS COUNCIL. Skill Development For Industry 4.0. A White Paper by BRICS Skill Development Working Group. Disponível em:

http://www.globalskillsummit.com/Whitepaper-Summary.pdf. Acesso em: 11 jul. 2018.

CALDERS, T.; CUSTERS, B.; What Is Data Mining And How Does It Work? Studies in Applied Philosophy, Epistemology and Rational Ethics. v. 3, p. 27-42, 2013.

https://doi.org/10.1007/978-3-642-30487-3 2

CAMARINHA-MATOS, L. M.; AFSARMANESH, H.; Collaborative Systems For Smart Environments: Trends And Challenges. IFIP Advances in Information and

Communication Technology. v. 434, p. 3-15, 2014. https://doi.org/10.1007/978-3-662-447451

CHIEN, C. F.; DOU, R.; FU, W.; Strategic Capacity Planning For Smart Production: Decision Modeling Under Demand Uncertainty. Applied Soft Computing Journal. v. 68, p. 900-909, jul. 2018. https://doi.org/10.1016/j.asoc.2017.06.001 
DEV, N. K.; SHANKAR, R.; GUPTA, R.; DONG, J.; Multi-Criteria Evaluation Of Real-Time Key Performance Indicators Of Supply Chain With Consideration Of Big Data Architecture. Computers \& Industrial Engineering. 2018. https://doi.org/10.1016/j.asoc.2017.06.001

DOSSOU, P. E.; NACHIDI, M.; Modeling Supply Chain Performance. Procedia Manufacturing. v. 11, p. 838-845, 2017. https://doi.org/10.1016/i.promfg.2017.07.186

DUARTE, S.; CRUZ-MACHADO, V.; Exploring Linkages Between Lean And Green Supply Chain And The Industry 4.0. International Conference on Management Science and Engineering Management. p. 1242-1252, 2017. https://doi.org/10.1007/978-3-319-592800103

FENG, L.; ZHANG, X.; ZHOU, K.; Current Problems In China's Manufacturing And Countermeasures For Industry 4.0. Eurasip Journal on Wireless Communications and Networking. v. 2018, n. 1, dec. 2018. https://doi.org/10.1186/s13638-018-1113-6

FERRERO, R.; BEATTIE, E.; PHOENIX, J.; Sensor City-A Global Innovation Hub For Sensor Technology. IEEE Instrumentation and Measurement Magazine. v. 21, n. 1, article number 8278801, p. 4-5 e 16, fev. 2018. https://doi.org/10.1109/MIM.2018.8278801

GANDHI, S.; MANGLA, S. K.; KUMAR, P.; KUMAR, D.; A Combined Approach Using AHP And DEMATEL For Evaluating Success Factors In Implementation Of Green Supply Chain Management In Indian Manufacturing Industries. International Journal of Logistics Research and Applications. v. 19, n. 6, p. 537-561, 2016. https://doi.org/10.1080/13675567.2016.1164126

GÖKALP, E.; SENER, U.; EREN, P. E.; Development Of An Assessment Model Forindustry 4.0: Industry 4.0-MM. International Conference on Software Process Improvement and Capability Determination, p.128-142, 2017. https://doi.org/10.1007/978-3-319-67383-7 10

GOVINDAN, K.; CHENG, T. C. E.; MISHRA, N.; SHUKLA, N.; Big Data Analytics And Application For Logistics And Supply Chain Management. Transportation Research Part E. v. 114, p. 343-349, jun. 2018. https://doi.org/10.1016/j.tre.2018.03.011

GUO, X.; ZHU, Z.; SHI, J.; Integration Of Semi-Fuzzy SVDD And CC-Rule Method For Supplier Selection. Expert Systems with Applications. n. 41, p. 2083-2097, 2014. https://doi.org/10.1016/i.eswa.2013.09.008

HOFMANN, E.; RÜSCH, M.; Industry 4.0 And The Current Status As Well As Future Prospects On Logistics. Computers in Industry. v. 89, p. 23-34, ago. 2017. https://doi.org/10.1016/j.compind.2017.04.002

JABBOUR, A. B. L. S.; JABBOUR, C. J. C.; FILHO, M. G.; ROUBAUD, D.; Industry 4.0 And The Circular Economy: A Proposed Research Agenda And Original Roadmap For Sustainable Operations. Annals of Operations Research. p. 1-14, fev. 2018.

JAYARAM, A.; Lean Six Sigma Approach For Global Supply Chain Management Using Industry 4.0 And liot. IC3I 2016. Article number 7917940, p. 89-94, 2-16. https://doi.org/10.1109/IC3I.2016.7917940

JUHÁSZ, J.; BÁNYAI, T.; What Industry 4.0 Means for Just-In-Sequence Supply in Automotive Industry? Lecture Notes in Mechanical Engineering. n. 9783319756769, p. 226-240, 2018. https://doi.org/10.1007/978-3-319-75677-6 19 
KIEL, D.; MÜLLER, J. M.; ARNOLD, C.; VOIGT, K. I.; Sustainable Industrial Value Creation:Benefits And Challenges Of Industry 4.0. International Journal of Innovation Management. v. 21, n. 8, 2017. https://doi.org/10.1142/S1363919617400151

KIM, SUWON; KIM, SEONGCHEOL; A Multi-Criteria Approach Toward Discovering Killer lot Application In Korea. Technological Forecasting \& Social Change. n. 102, p. 143-155, 2016. https://doi.org/10.1016/j.techfore.2015.05.007

LAMBERT, D. M.; COOPER, M. C.; Issues in Supply Chain Management. Industrial Marketing Management. v. 29, n. 1, p. 65-83, jan. 2000. https://doi.org/10.1016/S0019$\underline{8501(99) 00113-3}$

LEE, J.; KAO, H. A.; YANG, S.; Service Innovation And Smart Analytics For Industry 4.0 And Big Data Environment. Procedia CIRP. v. 16, p. 3-8, 2014. https://doi.org/10.1016/j.procir.2014.02.001

LOUW, L.; WALKER, M.; Design And Implementation Of A Low Cost RFID Track And Trace System In A Learning Factory. Procedia Manufacturing. v. 23, p. 255-260, 2018. https://doi.org/10.1016/i.promfg.2018.04.026

LU, Y.; XU, X.; Resource Virtualization: A Core Technology For Developing Cyber-Physical Production Systems. Journal of Manufacturing Systems. v. 47, p. 128-140, abr. 2018. https://doi.org/10.1016/j.jmsy.2018.05.003

LUTHRA, S.; GARG, D.; MANGLA, S. K.; BERWAL, Y. P. S.; Analyzing Challenges To Internet Of Things (lot) Adoption And Diffusion: An Indian Context. Procedia Computer Science. v. 125, p. 733-739, 2018. https://doi.org/10.1016/j.procs.2017.12.094

LUTHRA, S.; MANGLA, S. K.; Evaluating Challenges To Industry 4.0 Initiatives For Supply Chain Sustainability In Emerging Economies. Process Safety and Environmental Protection. v. 117, p. 168-179, jul. 2018. https://doi.org/10.1016/i.psep.2018.04.018

MARQUES, M.; AGOSTINHO, C.; ZACHAREWICZ, G.; JARDIM-GONÇALVES, R.; Decentralized Decision Support For Intelligent Manufacturing In Industry 4.0. Journal of Ambient Intelligence and Smart Environments. v. 9, p. 299-313, 2017. https://doi.org/10.3233/AIS-170436

MCBURNEY, M. K.; NOVAK, P. L.; What Is Bibliometrics And Why Should You Care? IEEE International Professional Communication Conference. p. 108-114, 2002.

MOKTADIR, M. A.; ALI, S. M.; KUSI-SARPONG, S.; SHAIKH, M. A. A; Assessing Challenges For Implementing Industry 4.0: Implications Forprocess Safety And Environmental Protection. Process Safety and Environmental Protection. abr. 2018. https://doi.org/10.1016/i.psep.2018.04.020

MÜLLER, J.; DOTZAUER, V.; VOIGT, K.; I.; Industry 4.0 And Its Impact On Reshoring decisions Of German Manufacturing Enterprises. Supply Management Research. p. 165179, 2017. https://doi.org/10.1007/978-3-658-18632-6 8

MÜLLER, J. M.; BULIGA, O.; VOIGT, K. I.; Fortune favors the prepared: How SMEs approach business model innovations in Industry 4.0. Technological Forecasting and Social Change. 2018. https://doi.org/10.1016/i.techfore.2017.12.019 
NAGY, G.; BÁNYAINÉ TÓTH, Á.; LLÉS, B.; GLISTAU, E.; Analysis Of Supply Chain Efficiency In Blending Technologies. Lecture Notes in Mechanical Engineering. $\mathrm{n}$. 9783319756769, p. 280-291, 2018. https://doi.org/10.1007/978-3-319-75677-6 23

NICOLETTI, B.; The Future: Procurement 4.0. Agile Procurement. p. 189-230, 2018. https://doi.org/10.1007/978-3-319-61085-6 8

O'DONOVAN, P.; GALLAGHER, C.; BRUTON, K.; O'SULLIVAN, D. T. J.; A Fog Computing Industrial Cyber-Physical System For Embedded Low-Latency Machine Learning Industry 4.0 Applications. Manufacturing Letters. V. 15, p. 139-142, jan. 2018.

https://doi.org/10.1016/i.mfglet.2018.01.005

PERKINS, J.; JORGENSEN, A. K.; BARTON, L.; COX, S.; Building Supply Chain

Relationships With Knowledge Management: Engineering Trust In Collaborative Systems.

ICEIS 2003. v. 4, p. 63-70. 2003.

PEREIRA, T.; BARRETO, L.; AMARAL, A.; Network And Information Security Challenges Within Industry 4.0 Paradigm. Procedia Manufacturing. v. 13, p. 1253-1260, 2017.

https://doi.org/10.1016/..promfg.2017.09.047

PETRISOR, I.; COZMIUC, D.; Global Supply Chain Management Organization At Siemens In The Advent Of Industry 4.0. Global Intermediation and Logistics Service Providers. p. 123-142, 2017. https://doi.org/10.4018/978-1-5225-2133-4.ch007

PFEIFFER, S.; The Vision Of "Industrie 4.0" In The Making - A Case Of Future Told, Tamed, And Traded. Nanoethics - University of Hohenheim. 2017. https://doi.org/10.1007/s11569$\underline{016-0280-3}$

PFOHL, H. C.; YAHSI, B.; KURNAZ, T.; Concept And Diffusion-Factors Of Industry 4.0 In The Supply Chain. Dynamics in Logistics. p. 381-390, 2017. https://doi.org/10.1007/978-3$\underline{319-45117-6 \quad 33}$

PUJARA, S. M.; SATYANARAYANA, K. V.; Internet Of Things And Libraries. Annals of Library and Information Studies. v. 62, p. 186-190, set. 2015.

QURESHI, K. A.; MOHAMMED, W. M.; FERRER, B. R.; LASTRA, J. L. M.; AGOSTINHO, C.; Legacy Systems Interactions With The Supply Chain Through The C2NET Cloud-Based Platform. IEEE Xplore Digital Library. Article number 8104862, p. 725-731, nov. 2017. https://doi.org/10.1109/INDIN.2017.8104862

RAS, E.; WILD, F.; STAHL, C.; BAUDET, A.; Bridging The Skills Gap Of Workers In Industry 4.0 By Human Performance Augmentation Tools: Challenges And Roadmap. Petra 2017. p. 428-432, jun. 2017. https://doi.org/10.1145/3056540.3076192

RÖSCHINGER, M.; KIPOURIDIS, O.; GÜNTHNER, W. A. A Service-Oriented Cloud Application For A Collaborative Tool Management System. ICIMSA. Article number 7503987, jul. 2016. https://doi.org/10.1109/ICIMSA.2016.7503987

SAATY, T. L.; VARGAS, L. G.; Estimating Technological Coefficients By The Analytic Hierarchy Process. University of Pennsylvania. The Wharton School. v. 13, n. 6, p. 333336, 1979. https://doi.org/10.1016/0038-0121(79)90015-6

SACHDEVA, N.; OBHEROI, R. K.; SRIVASTAVA, A.; NEHAL, S. K.; Diffusion Of Industry 4.0 In Manufacturing Sector-An Innovative Framework. International Conference on 
Infocom Technologies and Unmanned Systems. p. 1-5, fev. 2018.

https://doi.org/10.1109/ICTUS.2017.8286025

SANTOS, M. Y.; SÁ, J. O.; ANDRADE, C.; VALE LIMA, F.; COSTA, E.; COSTA, C.; MARTINHO, B.; GALVÃO, J.; A Big Data System Supporting Bosch Braga Industry 4.0 Strategy. International Journal of Information Management. v. 37, n. 6, p. 750-760, dec. 2017. https://doi.org/10.1016/j.ijinfomgt.2017.07.012

SANTOS, M. Y.; SÁ, J. O.; COSTA, C.; GALVÃO, J.; ANDRADE, C.; MARTINHO, B.; LIMA, F.; V.; COSTA, E.; A Big Data Analytics Architecture For Industry 4.0. World Conference on Information Systems and Technologies. p. 175-184, 2017. https://doi.org/10.1007/978-3319-56538-5 19

SAVTSCHENKO, M.; SCHULTE, F.; VOB, S.; IT Governance For Cyber-Physical Systems: The Case Of Industry 4.0. International Conference of Design, User Experience, and Usability. p. 667-676, 2017. https://doi.org/10.1007/978-3-319-58634-2 48

SCHUH, G.; ANDERL, R.; GAUSEMEIER, J.; HOMPEL, M. T.; WAHLSTER, W.; Industrie 4.0 Maturity Index - Managing The Digital Transformation Of Companies (acatech STUDY). ISSN 2192-6174. 2017.

SHAMIM, S.; CANG, S.; YU, H.; LI, Y.; Examining The Feasibilities Of Industry 4.0 for The Hospitality Sector With The Lens Of Management Practice. Energies. n. 10, v. 4, p. 499, 2017. https://doi.org/10.3390/en10040499

SHAMIM, S.; CANG, S.; YU, H.; LI, Y.; Management Approaches For Industry 4.0: A Human Resource Management Perspective. IEEE Congress on Evolutionary Computation. Article number 7748365, p. 5309-5316, nov. 2016. https://doi.org/10.1109/CEC.2016.7748365

SIMATUPANG, T. M.; SRIDHARAN, R.; Complementarities In Supply Chain Collaboration. Industrial Engineering and Management Systems. v.17, n. 1, p. 30-42, mar. 2018. https://doi.org/10.7232/iems.2018.17.1.030

SOMMER, L.; Industrial Revolution-Industry 4.0: Are German Manufactur-Ing Smes The First Victims Of This Revolution? Journal of Industrial Engineering and Management. v. 8, n. 5, p. 1512-1532, 2015. https://doi.org/10.3926/iiem.1470

THAKARE, Y. B.; MUSALE, S. S.; GANORKAR, S. R. A Technological Review Of RFID \& Applications. IET Conference Publications. n. 535, p. 65-70, 2008.

https://doi.org/10.1049/cp:20080146

THEORIN, A.; BENGTSSON, K.; PROVOST, J.; LIEDER, M.; JOHNSSON, C.; LUNDHOLM, T.; LENNART-SON, B.; An Event-Driven Manufacturing Information System Architecturefor Industry 4.0. International Journal of Production Research. v. 55, n. 5, p. 1297-1311, 2017. https://doi.org/10.1080/00207543.2016.1201604

TJAHJONO, B.; ESPLUGUES, C.; ARES, E.; PELAEZ, G.; What Does Industry 4.0 Mean To Supply Chain? Procedia Manufacturing. v. 13, p. 1175-1182. 2017.

https://doi.org/10.1016/j.promfg.2017.09.191

TUPA, J.; SIMOTA, J.; STEINER, F.; Aspects of Risk Management Implementation for Industry 4.0. Procedia Manufacturing. v. 11, p. 1223-1230, 2017.

https://doi.org/10.1016/..promfg.2017.07.248 
TUPTUK, N.; HAILES, S.; Security Of Smart Manufacturing Systems. Journal of Manufacturing Systems. v. 47, p. 93-106, abr. 2018.

https://doi.org/10.1016/j.jmsy.2018.04.007

VITORINO FILHO, V. A.; CAMARGO JÚNIOR, J. B.; PIRES, S. R. I.; ARGOUD, A. R. T. T.; The International Academic Production In Practices And Initiatives Of Supply Chain Collaborative Management: Bibliometric Study. Revista Produção Online. Florianópolis, SC, v.17, n. 2, p. 567-591, 2017. https://doi.org/10.14488/1676-1901.v17i2.2462

WANG, J. P.; SUN, Y. C.; ZHANG, W. S.; THOMAS, I.; DUANS, H.; SHI, Y. K.; Large-Scale Online Multitask Learning And Decision Making For Flexible Manufacturing. IEEE

Transactions on Industrial Informatics. v.12, n. 6, article number 7446300, p. 2139-2147, dec. 2016. https://doi.org/10.1109/TII.2016.2549919

WANG, S.; WAN, J.; LI, D.; ZHANG, C.; Implementing Smart Factory Of Industrie 4.0: An Outlook. International Journal of Distributed. jan. 2016.

https://doi.org/10.1155/2016/3159805

WANG, Y.; MA, H. S.; YANG, J. H.; WANG, K. S.; Industry 4.0: A Way From Mass Customization To Mass Personalization Production. Advances in Manufacturing. v. 5, n. 4, p. 311-320, dec. 2017. https://doi.org/10.1007/s40436-017-0204-7

XU, B.; ZHANG, L. A.; Clock Based Framework For Specifying And Modeling The Time Constraints Of Cyber Physical Systems. IEEE 11th International Conference on Dependable. Article number 6844377, p. 288-295, 2013.

https://doi.org/10.1109/DASC.2013.77

YAN, H.; HUA, Q.; WANG, Y.; WEI, W.; IMRAN, M.; Cloud Robotics In Smart Manufacturing Environments: Challenges And Countermeasures. Computers \& Electrical Engineering. v. 63, p. 56-65, out. 2017. https://doi.org/10.1016/j.compeleceng.2017.05.024

YU, H.; SOLVANG, W. D.; Enhancing The Competitiveness Of Manufacturers Through Small-Scale Intelligent Manufacturing System (SIMS): A Supply Chain Perspective. ICITM. Article number 7917904, p. 101-107, maio 2017. https://doi.org/10.1109/ICITM.2017.7917904

ZENG, W.; ZHAO, J.; LIU, M.; Several Public Commercial Clouds And Open Source Cloud Computing Software. ICCSE 2012. Article number 6295264, p. 1130-1133, 2012.

https://doi.org/10.1109/ICCSE.2012.6295264

ZHONG, R. Y.; XU, X.; KLOTZ, E.; NEWMAN, S. T.; Intelligent Manufacturing In The Context Of Industry 4.0: A Review. Engineering. v. 3, n. 5, p. 616-630, 2017.

https://doi.org/10.1016/J.ENG.2017.05.015

ZHOU, K.; LIU, T.; ZHOU, L.; Industry 4.0: Towards Future Industrial Opportunities And Challenges. 12th IEEE International Conference on Fuzzy Systems. p. 2147-2152, 2015. https://doi.org/10.1109/FSKD.2015.7382284

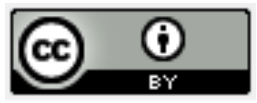

Artigo recebido em: 19/11/2018 e aceito para publicação em: 29/05/2019 DOI: http://dx.doi.org/10.14488/1676-1901.v19i2.3460 